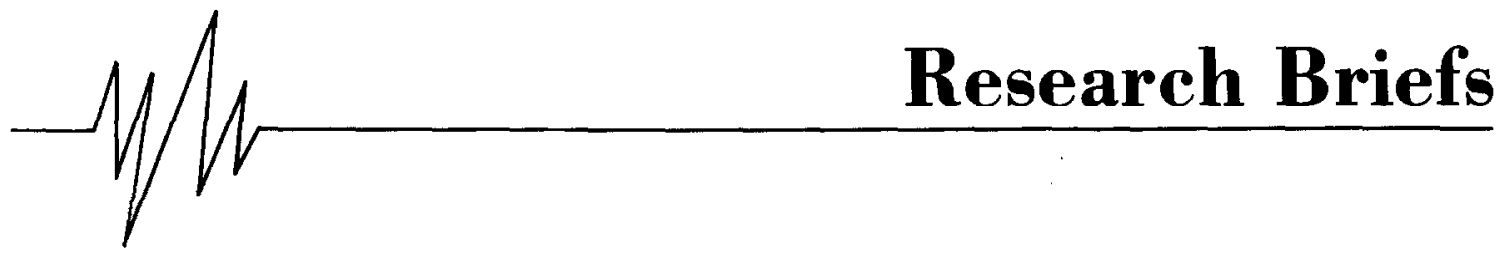

\section{Nutrition Locus of Control and Dietary Behaviors of Pregnant Women}

\author{
Ninfa Saturnino Springer, Erna-Lynne Bogue, \\ Marilynn Arnold, Dawn Yankou, and Deborah Oakley
}

B EHAVIOR PATTERNS are a key factor in preventing illness and maintaining health (Department of Health and Human Services, 1991). Self-care behaviors are encouraged as a way to maximize personal health and limit health care expenses. Interventions to enhance self-care efforts have met with limited success because changes in daily living are often difficult to sustain (Evans \& Hall, 1978). Because self-direction, as measured by the locus of control orientation, is believed to influence self-care efforts, educational and clinical programs based on locus of control perspectives have been suggested as one means to promote self-care behaviors (Houts \& Warland, 1989; Muhlenkamp \& Nelson, 1981).

The locus of control construct, as derived from Rotter's social learning theory (Rotter, 1954), has two dimensions. Internal locus of control is the extent to which one believes in one's personal ability to control outcomes. External locus of control is the extent to which one believes events are beyond personal control. External control is divided into two subdimensions (a) powerful others locus of control describes the extent to which one believes that others, such as physicians, the health care system, family, or friends, are responsible for outcomes; and (b) chance locus of control describes the extent to which one believes outcomes are caused by factors such as chance, fate, or luck over which no one has control. Because the dimensions are considered to be independent, a person's locus of control can be high or low in one or more dimensions. In addition, each dimension can vary according to specific situations, such as weight loss or pregnancy.

To more accurately address health care issues,
Wallston, Wallston, and DeVellis (1978) developed the Multidimensional Health Locus of Control Scale. High internal scores have been positively associated with such self-care behaviors as information seeking, reduction of smoking behaviors (Wallston and Wallston, 1978), and adherence to blood pressure medication protocol (Kerr, 1986). Results from other studies have been mixed. One reason for inconsistent findings has been the use of general scales to assess a specific expectancy or behavioral domain.

Using a sample of 943 women, this report examincs the relationship of the subjects' nutrition locus of control to dietary behavior during pregnancy. Nutrition during this period is an important domain to study because food choices significantly affect pregnancy outcomes (Committee on Nutritional Status During Pregnancy and Lactation, 1990).

\section{METHOD}

This report presents data from the first 943 pregnant women who consented to participate in a 5 -year research project comparing the services of certified nurse midwives and obstetricians and the outcomes among the women served by these two sets of service providers. Only those women who met the criteria for low to moderate obstetric risk were asked to participate in the study. The demographic characteristics of the women are presented in Tablc 1. Ovcrall, these pregnant women were highly educated and almost half had household incomes over $\$ 40,000$. Only $10(1 \%)$ lived alone.

The women completed a nutrition locus of control (NI.OC) scale as part of a larger questionnaire administered during their first prenatal visit. The scale contained statements extracted from one developed by Eden, Kamath, Kohrs, and Olson (1984). The present study used a reduced scale of nine statements (three each representing internal, external powerful others, and external chance) instead of the 23-statement scale because of concern for respondent burden in a clinic setting. Respondents indicated their level of agreement with statements on the scale using a 6-point Likert-type for- 
Table 1. Demographic Characteristics of Pregnant Women

\begin{tabular}{lrr}
\hline & $n$ & $\%$ \\
\hline Education $(n=943)$ & 33 & 3.5 \\
i1 years or less & 131 & 13.9 \\
High school graduate & 203 & 21.5 \\
Some college & 216 & 22.9 \\
College graduate & 360 & 38.2 \\
Some graduate school & & \\
Annual family income $(n=918)$ & 155 & 16.9 \\
Under $\$ 19,000$ & 145 & 15.8 \\
$\$ 20-29,000$ & 158 & 17.2 \\
$\$ 30-39,000$ & 143 & 15.6 \\
$\$ 40-49,000$ & 317 & 34.5 \\
$\$ 50,000$ and above & & \\
Persons in household $(n=943)$ & 10 & 1.1 \\
Live alone & 416 & 44.1 \\
One other person & 358 & 38.0 \\
Two other people & 159 & 16.9 \\
Three or more other people & & \\
\hline
\end{tabular}

mat, ranging from "strongly disagree" (rated as $l$ ) to "strongly agree" (rated as 6).

Respondents also reported their daily intake (i.e., the number of times foods from particular groups were eaten). These data provided a rough measure of food selection patterns. In addition, women were asked to complete a 1-day food diary. Because this required additional time and effort, it is not surprising that only $545(58 \%)$ of the 943 pregnant women completed this form. The data were analyzed by the Food Processor II software program (ESHA) Research, 1990), which calculated the percent of recommended daily allowances (RDA) for total energy, protein, vitamins, and minerals (Food and Nutrition Board, National Academy of Sciences, 1989) and percent of dietary goals (DG) for fat energy, saturated fat, mono- and polyunsaturated fats, cholesterol, dietary fiber, and sodium (U.S. Senate Select Committee on Nutrition and Human Needs, 1977).

\section{RESULTS AND DISCUSSION}

Factor analysis and construct validity using data from 943 responses replicated the internal NLOC items but produced a single external NLOC dimension with five items. The revised NLOC Scale therefore contained eight instead of nine items (Table 2). Cronbach's alpha for the internal NLOC was acceptably high (.67), whereas the external NLOC showed adequate internal consistency (.64).
Significant relationships were found between the revised NLOC scale and dietary behaviors of the pregnant women measured both in terms of food selection patterns (number of times foods from particular groups were eaten in a day) and the adequacy of these selections in meeting nutritional needs (percent of RDA and DG). Pearson correlation coefficients were significant in the expected directions. Pregnant women who scored high on the internal NLOC scale ate fruits and vegetables, breads and grain products, dairy products, and vegetable proteins significantly more often and ate meat less often than women scoring lower. In contrast, women who scored high on the external NLOC scale reported eating fruits and vegetables, breads and grain products, and dairy products significantly less often and ate red meats more often than women scoring lower.

Nutrient intake data were available from 544 women who completed a 1-day food diary. Although single-day food records do not represent typical individual food intakes, they provide trends in dietary quality, particularly with the large sample in this study (Basiotis, Welsh, Dronin, Kelsay, \& Mertz, 1987). Most women reported diets near or above the RDA or DG for most nutrients. Mean intakes for copper and iron were the lowest at $58 \%$ and $70 \%$ of the RDA, respectively. However, most of the women were taking multivitaminmineral supplements.

For many variables, no significant correlations were found between either the internal or the external NLOC scale and the RDA or DG. However, the few significant correlations with the internal

\section{Table 2. Revised Internal and External NLOC Statements (mean score, SD, Cronbach's alpha)}

\footnotetext{
Internal $(5.65 \pm 0.57,0.67)$

I generally try to choose healthy foods.

I believe that I have a responsibility to choose foods that are good for me.

I would be willing to change the way I eat if it was better for me.

External $(1.96 \pm 0.87,0.64)$

Usually I eat whatever I feel like eating without thinking whether it is nutritious.

It would be simply a matter of luck if I happened to get healthy food every day.

I do not think what I eat will affect my health.

I would eat a healthier diet if I could afford it.

There is not much I can do to change my eating habits.
} 
NLOC scale were all in the expected direction: pregnant women who scored high on the internal NLOC scale had diets with levels higher than the RDA for vitamin $A$, riboflavin, vitamin $B_{6}$, calcium, magnesium, and potassium. In contrast, the significant correlations with the external NLOC scale were all negative: pregnant women who scored high on external NLOC reported diets that were less adequate in riboflavin, calcium, phosphorus, and dietary fiber. These findings suggest that women with higher internal locus of control scores consumed diets higher in some nutrients than did those with higher external locus of control scores.

\section{NURSING IMPLICATIONS}

The revised NLOC scale provides an easily determinable measure of women's beliefs about the control of their dietary behavior during pregnancy. The revised scale minimizes the amount of time required for respondents. Although the revised scale does not differentiate between the two subdimensions of external NLOC, it does identify two basic patterns of approach to food. These dimensions have clinical implications during pregnancy.

The internal NLOC dimension may suggest a pattern of dealing with food in which women act on their knowledge of good nutrition by choosing foods that provide an adequate level of desirable nutrients and by avoiding those that are believed to be unhealthy. A pregnant woman scoring high on the internal NLOC scale may also be more likely to seek out nutritional information to improve her dict than those with low scores on this dimension. Nutrition education with these women may focus on providing information to facilitate independent decision making.

The external NLOC dimension, in contrast, appears to point to a different pattern of food behavior. High external scores appear to reflect strong agreement with statements related to the attitude that eating habits are not important to health or to circumstances that constrain their eating choices. Pregnant women who score high on this scale may report limited variety in their diets and may consume less adequate levels of important nutrients. Because external factors significantly influence their food choices, these women may respond to external reinforcement from health care professionals to practice optimal nutrition during pregnancy. Women who score high on the external
NLOC may benefit from being told specifically what to eat. Therefore, counseling might include guidance or support for changes in the location and scheduling of eating or the selection and preparation of their food. Other women may benefit from instruction in the relationship between nutrition, their health, and the health of their babies. For women constrained by finances, nutrition education could focus on specific low-cost ways of achieving adequate nutrition during pregnancy and might include referrals to agencies such as the Supplemental Feeding Program for Women, Infants, and Children.

Because the internal and external nutrition locus of control dimensions are considered to be independent, some women may score high on both dimensions. For these women, both types of nutrition interventions just described would be relevant and important.

The revised scale can be used for research as well as clinical purposes. It could be used in further studies to determine its relative predictive power in comparison with measures of other specific locus of control domains, such as those pertaining to pregnancy. This shortened version minimizes the amount of time required for respondents and therefore provides a useful approach for nutrition interventions not only during pregnancy but also for other chronic health problems as well. It is suggested that these studies include continuing assessment of the scale's reliability and validity.

\section{ACKNOWLEDGMENT}

The authors express appreciation to Karen Yost, MSW and William Mayes for data entry and management that led to this report.

\section{REFERENCES}

Basiotis, P.P., Welsh, S.O., Dronin, F.J., Kelsay, J.L., \& Mertz, W. (1987). Number of days of foud intake records required to estimate individual and group intakes with defined confidence. Journal of Nutrition, 117, 1638-1641.

Committee on Nutritional Status During Pregnancy and Lactation. Food and Nutrition Board, Institute of Medicine. National Academy of Sciences. (1990). Nutrition during pregnancy (pp. 37-62). Washington, DC: National Academy Press.

Department of Health and Human Services. (1991). Healthy People: The Surgeon General's Report on Health Promotion and Disease Prevention (pp. 19-22). Washington, DC: U.S. Government Printing Office.

Eden, I., Kamath, S.K., Kohrs, M.B., \& Olson, R.E. (1984). Perceived control of nutrition behavior: A study of the locus of control theory among healthy subjects. Journal of the American Dietetic Association, 84, 1334-1339. 
ESHA Research. (1990). The Food Processor 11. Nutrition and diet analysis system. Version 3.0. Salem, OR: ESHA Research.

Evans, R., \& Hall, Y. (1978). Social-psychologic perspective in motivating changes in eating behavior. Journal of the American Dietetic Association, 72, 378-383.

Houts, S.S., \& Warland, R.H. (1989). Rotter's social leaming theory of personality and dietary behavior. Psychological Reports, 21, 172-179.

Kerr, J. (1986). Multidimensional health locus of control, adherence, and lowered diastolic blood pressure. Heart and Lung, 15, 87-93.

Muhlenkamp, A.E., \& Nelson, A.M. (1981). Health locus of control, valucs, and wcight reduction bchavior. Journal of Psychosocial Nursing in Mental Health Services, 19(11), 2126.

National Academy of Sciences. National Research Council. Food and Nutrition Board. (1989). Recommended dietary allowances (9th ed.). Washington, DC: National Academy Press.

Rotter, J.B. (1954). Social learning and clinical psychology (pp. 105-183). New York, NY: Prentice Hall, Inc.

U.S. Senate Select Committee on Nutrition and Human Needs. (1977). Dietary goals for the United States (\#052-07004376-8). Washington, DC: U.S. Government Printing Office.

Wallston, B.S., \& Wallston, K.A. (1978). Locus of control and health: A review of the literature. Health Education Monographs 6, 107-117.
Wallston, K.A., Wallston, B.S., \& DeVellis, R. (1978) Development of the multidimensional health locus of control (MHLC) scales. Health Education Monographs 6, 160-170.

From the School of Nursing, and the Michigan Diabetes Research and Training Center, University of Michigan, Ann Arbor, $M I$

Ninfa Saturnino Springer, MS, PhD, RD: Associate Professor, Division of Health Promotion and Risk Reduction, School of Nursing; Erna-Lynne Bogue, AM, MA, ACSW: Doctoral Candidate in Social Work and Social Sciences, Graduate Research Assistant, School of Nursing; Marilynn Arnold, MS, RD, CDE: Nutrition Specialist, Michigan Diabetes Research and Training Center; Dawn Yankou, MHSc, RN: Doctoral Candidate and Graduate Research Assistant, School of Nursing. University of Michigan; and Deborah Oakley, PhD: Professor, Center for Nursing Research, School of Nursing, University of Michigan.

Supported in part by Grant RO1 NR01887 from the National Center for Nursing Research in the National Institutes of Health.

Reprints are unavailable.

Copyright (C) 1994 by W.B. Saunders Company $0897-1897 / 94 / 0701-0006 \$ 5.00 / 0$ 